with cadaveric skin if the patient has insufficient donor skin. Artificial skin substitutes are being increasingly used with good results (see a later article in this series). Several layers of dressings are used to minimise shear at the site of skin grafting. These should not be too tight as swelling often occurs after a burn injury.

Once a burn has healed, the area should be regularly moisturised and protected from the sun by sunblock cream or clothing. Physiotherapy may be required to prevent burn contractures.

\section{Further reading and resources}

- Herndon D. Total burn care. 2nd ed. London: Saunders, 2002.

- National Burn Care Review. National burn injury referral guidelines. In: Standards and strategy for burn care. London: NBCR, 2001:68-9.

- Burnsurgery.org (a website designed to be a comprehensive educational tool for burn care professionals worldwide) www.burnsurgery.org

Alex Benson is specialist registrar in plastic surgery in the Mersey Regional Plastic Surgery Unit, Whiston Hospital, Liverpool. William A Dickson is consultant burns and plastic surgeon and Dean E Boyce is consultant hand and plastic surgeon in the Welsh Centre for Burns and Plastic Surgery, Morriston Hospital, Swansea.

The ABC of wound healing is edited by Joseph E Grey (joseph.grey@cardiffandvale.wales.nhs.uk), consultant physician, University Hospital of Wales, Cardiff and Vale NHS Trust, Cardiff, and honorary consultant in wound healing at the Wound Healing Research Unit, Cardiff University, and by Keith G Harding, director of the Wound Healing Research Unit, Cardiff University, and professor of rehabilitation medicine (wound healing) at Cardiff and Vale NHS Trust. The series will be published as a book in summer 2006 .
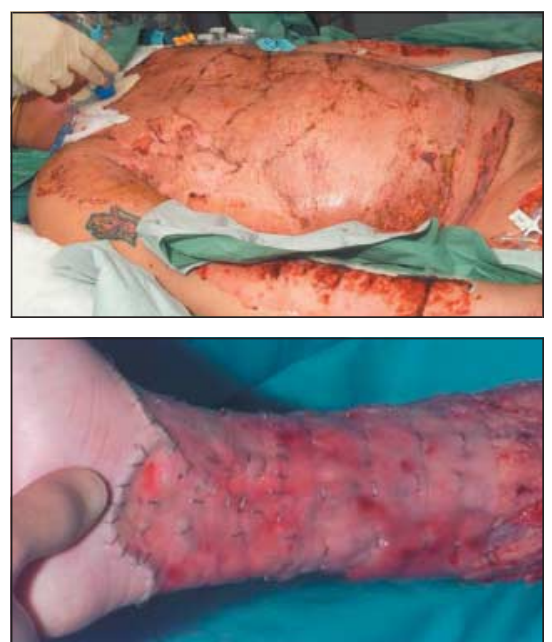

Top: Full thickness burns of the abdomen have been excised and closed with split thickness skin grafts. Bottom: Artificial skin substitute used to cover full thickness burn
Prevention of burns is key: the main improvement in reduction of burns in the UK over the past 40 years has been the introduction of legislation to reduce the flammability of clothing, furniture, and fireworks and of proper labelling of inflammable materials

Competing interests: For series editors' competing interests, see the first article in this series.

BMJ 2006;332:649-52

\title{
bmjlearning.com
}

\section{The Napsterisation of learning}

At BMJ Learning, we like to think that we are creating something new-an evidence based, interactive, and interdisciplinary learning service. But sometimes I wonder how different it is from what has gone before. In the past, learning was about teachers giving information from the lectern to the grateful recipients below. We like to think that we are interactive and that we engage learners rather than lecturing them. But critics of BMJ Learning would say that it is still a large compendium of learning resources that learners must work their way through. Certainly the internet enables us to communicate large amounts of new and easily updated knowledge quickly and easily - but that is just using a small part of its potential.

In 2000 , just as dot com was turning into dot bomb, Shawn Fanning founded Napster-a system whereby internet users could share music files. It is an idea that is now changing the face of the internet. There is no large behemoth bestowing resources or wisdom from on high-rather it is about putting people in touch with each other. How can this help with learning? Well, no learning resource, no matter how big, can answer all possible questions. Our recent module on hepatitis B gives an overview on recent advances on how best to treat patients with this infection. But what if you are caring for a patient with hepatitis B who also has hepatitis $\mathrm{C}$ and who is intolerant of interferon and who doesn't like taking drugs anyway? Our learning module won't be able to answer such a specific question, and it is likely that no learning resource will be able to do so. So what do you do? You could ask your colleagues down the hall, but what if they don't know either?

Another option is to go online and ask a colleague. The new discussion forum that we have added to www.bmjlearning.com enables you to do exactly that. Like the Napster model, it is a peer to peer system that puts end users in touch with each other. Learners and teachers have always shared with each other-lecture notes, presentations, quotes, etc-and a learning forum enables you to do just that, but with thousands of potential colleagues rather than just one. You will also get the question that is important to you answered-rather than the question that is important to the author.

Critics of peer to peer systems say that they can result in chaos and that you cannot guarantee that the answer to your question is correct. But, as Donald Clarke of EPIC says, "regular internet users accept the trade-off between chaos and usefulness." In addition, we moderate our forum to ensure that the postings are of high quality and that users respect patient confidentiality. Also a form of natural selection ensures that the best postings are the ones that everyone sees while the poor ones gradually fade from view. As the peer to peer gurus say, we now have "connection as well as collection."

Kieran Walsh clinical editor, BMJ Learning (bmjlearning@bmjgroup.com)

1 Clark D. White paper: Napsterisation of e-learning (P2P). www.epic.co. $\mathrm{uk} /$ content/resources/white_papers/p2p.htm (accessed 6 Dec 2005). 